\title{
Unity, Mereology and Connectivity
}

\author{
Farid Masrour \\ Harvard University
}

During the past few decades, unity of consciousness has been a central topic in philosophy of mind and cognitive science. And although Bayne's book comes in a context where some serious work has been done on the topic, the book significantly contributes to the discussion by introducing a fresh set of new ideas and arguments. ${ }^{1}$ Bayne also brings together sober philosophical analysis with careful attention to the empirical literature on the topic. I congratulate Bayne for his excellent contribution.

My goal here is to ask Bayne to expand on a few topics. I ask him to do so because I am somewhat puzzled or skeptical about Bayne's views on these topics. In $\S 1$, I raise a few questions about Bayne's mereological view and the thesis that consciousness is necessarily unified. In $\S 2$ and $\S 3$ I offer an alternative view of unity of consciousness and contrast it with Bayne's view. I call this view the connectivity account. These sections prepare the ground for the main question of this article: why should we prefer Bayne's mereological view to the connectivity view? Throughout the article, I use "unity" and "unity of consciousness" to refer to phenomenal unity.

\section{Bayne's Account: A Few Questions}

An important task for a philosophical account of unity is to answer what we might call the grounding question: what are the set of fundamental personal level facts, if any, in virtue of which, phenomenally conscious states are unified, when they are unified? ${ }^{2}$ By personal level facts I mean those that are available to consciousness. This is of course a rough characterization. But it will do for our purposes. Phenomenal facts and facts about

${ }^{1}$ See Bayne and Chalmers 2003, Dainton 2006, Hurley 2002, Lockwood 1989, Peacocke 1994,

2 Throughout the paper, I use locutions such as "x obtains in virtue of $y$ " and " $x$ is grounded in $y$ " equivalently. The significance of using the relations of grounding in formulating metaphysical positions and its independence from notions such as supervenience and related modal notions has been extensively discussed in recent literature. See Fine 2010, 2012a, 2012b, Rosen 2010, Shaffer 2009 and the papers in Correia \& Schnieder 2012. 
conscious contents are paradigm cases of personal level facts. Facts about the neural mechanisms that underlie unity, for example, do not count as personal-level facts.

A primitivist about unity would answer the grounding question by holding that there are no phenomenal facts at a more fundamental level in virtue of which phenomenally conscious states are unified. Bayne, on the contrary, provides a substantive answer to this question in terms of mereological relations:

\section{The Mereological Thesis}

Conscious states are phenomenally unified in virtue of the fact that they occur as the parts of a single conscious state. ${ }^{3}$

On Bayne's view, when a set of conscious states is unified, its members are unified in virtue of the fact that there is a total state of consciousness of which the unified states are parts. Unity facts are thus grounded in a metaphysically more fundamental set of facts pertaining to the existence of a total conscious state and the obtaining of part-whole relations between the unified states and this total state. Bayne sometimes refers to this relation as subsumption.

My first question about Bayne's view has to do with the mereological thesis. Does Bayne have a mereology and if so, what is it? By a mereology I mean an account of the conditions in which there are experiential wholes containing experiential parts. ${ }^{4}$ Without a mereology, Bayne's view only tells us that part-whole facts are metaphysically more fundamental than facts about unity. That is, it takes a position about metaphysical priority. But in the absence of a mereology, it is not completely clear why one should take this position about priority. To see this, we can compare Bayne's Mereological Thesis with two other theses:

\section{The Neutral Mereological Thesis}

A set of conscious states are phenomenally unified iff they occur as the parts of a single conscious state.

\section{The Reverse Mereological Thesis}

A set of conscious states are parts of a whole conscious states in virtue of the fact that these states together form a phenomenally unified whole.

The Neutral Mereological Thesis does not take a position about the issue of priority. The Reverse Mereological Thesis, in contrast, puts unity at a more fundamental level than part-whole relations. It is not completely clear why one should prefer Bayne's Mereological Thesis to these rivals. And one might expect that a mereological account of conscious states would shed some light on this issue. So I think that it would be helpful if Bayne addressed this issue.

\footnotetext{
${ }^{3}$ Bayne 2010, ch.2

4 In Bayne \& Chalmers 2003, the subsumption relation is analyzed in terms of entailment relations among the contents of states. But Bayne seems to abandon this analysis in the book.
} 
A second substantive thesis in Bayne's book is what he calls the Unity Thesis:

\section{The Unity Thesis}

Necessarily, for any conscious subject of experience $(\mathrm{S})$ and any time $(\mathrm{t})$, the simultaneous states that $\mathrm{S}$ has at $\mathrm{t}$ are unified (and thus will be subsumed by a single conscious state-the subject's total conscious state. $)^{5}$

My second question is about the modal status of the Unity Thesis. Bayne holds that the necessity involved in this thesis is neither conceptual, nor metaphysical, nor grounded in the laws of nature. But what sense of necessity does he have in mind? Some parts of the text suggest that the conditions for unity and the conditions for consciousness are bound together in a manner that gives rise to this necessity:

The mechanisms underpinning consciousness function in such a way that the conscious states they generate always occur as the unified components of a single phenomenal field. ${ }^{6}$

If so, then one could say that the necessity is a mechanistic notion. There is an intimate relationship between consciousness and unity. But other parts of the text seem to be incompatible with this reading:

Perhaps there are surgical innovations or evolutionary developments that could bring about a division in the stream of consciousness; perhaps there are other species in which the unity of consciousness can be lost. ${ }^{7}$

If there is an intimate connection between unity and consciousness, then how could it be possible for the connection to break? Doesn't the fact that the connection can break tell us that there isn't an intimate connection between unity and consciousness? It would be helpful to know what the nature of this connection is.

Whatever the sense of necessity that is involved in the Unity Thesis might be, another question has to do with the motivation for embracing it. A good part of Bayne's book focuses on defending the thesis. In chapters 4-10, after addressing some methodological concerns, Bayne carefully reviews the empirical literature on some examples that have been traditionally regarded as cases in which unity breaks (hypnosis, schizophrenia, split brains, etc.), and argues that the empirical data is compatible with what he calls the switch model of consciousness. Since the switch model is compatible with the idea that consciousness is always unified, Bayne in effect undercuts the evidence for the claim that unity of consciousness breaks in some circumstances. Here, Bayne combines a very impressive review of the empirical literature with an excellent philosophical analysis. However, the gist of the reasoning in these parts is that the empirical data is compatible with the switch model. The reader is not offered much by way of a positive reason to embrace the Unity Thesis. So my third question is: What it the positive motivation for

${ }^{5}$ Bayne 2012, p.16

${ }^{6}$ Ibid., p.17

7 Ibid. 
embracing the Unity Thesis?

This question becomes more pressing if we adopt a naturalistic attitude toward unity. It is natural to hold that unity supervenes on some contingent brain condition. But if so, why hold that unity cannot break in some possible abnormal circumstance? Note that it is not clear why the constitutive connection between unity and consciousness would secure the Unity Thesis. If all that we mean by this connection is that every conscious state must be unified with some other conscious states, then it is not clear why it implies the Unity Thesis. For, there could be subjects with multiple streams of consciousness in whom every conscious state is unified with some other conscious state. Perhaps the connection between unity and consciousness is of a different sort. If so, it helps to know more about the connection.

My last question is about the epistemology of unity. Bayne does not just hold that our consciousness is unified at each moment. He also holds that we have some epistemic access to this fact. At least when consciousness is phenomenally unified, the fact that it is unified is introspectively accessible to us. Bayne thus holds the thesis that we have an introspection-based judgment to the effect that all of our conscious states are unified at each moment. He calls this the Unity Judgment:

\section{The Unity Judgment}

The introspection-based judgment that all of our conscious states at a moment are subsumed by a single state [Unified].$^{8}$

Bayne's claim that the Unity Judgment is based on introspection invites the reading that on his view the fact that consciousness is unified is given to introspection, as it were, in one act of introspecting. It is not that we introspectively find several local unities (unities among some but not all of the conscious states that we have) and then through some reasoning come to the conclusion that all of our conscious states are unified. We find global unity when we introspect. But then one might wonder how we might be able to have the whole phenomenal field under the purview of introspection. After all, it is plausible that introspection is subject to the limitations of working memory. So another question is: how could introspection provide direct support for the Unity Judgment?

\section{The Connectivity Account}

My aim in this section is to introduce a possible alternative to Bayne's mereological account. In order to set the stage for this alternative, I want to distinguish between two different types of personal-level theories of phenomenal unity. On some theories of phenomenal unity the most fundamental personal-level fact that grounds unity is a form of singularity or oneness. I call these accounts Newtonian account of unity because of their similarity to Newtonian views of space according to which, the most fundamental fact that grounds relations of co-spatiality between various points of a space is the fact

8 Ibid., p. 75 
that these points are parts of the same single space. In holding that phenomenally conscious states are unified in virtue of the fact that they are parts of a single total state of consciousness, Bayne seems to adopt a Newtonian account of unity. But, as shall see in the next section, this issue partly depends on Bayne's view about mereology. ${ }^{9}$

It is not, however, clear that we have to adopt a Newtonian view of phenomenal unity. Perhaps, unity is grounded in certain conditions over the local relations that obtain among experiences. The following passage from Nagel 1971 that Bayne also quotes can be interpreted as suggesting a view like this:

The experiences of a single person are thought to take place in an experientially connected domain, so that the relations among experiences can be substantially captured in experiences of those relations (Nagel 1971, p.407)

Under one reading, offers a view of unity that builds global unity from local relations. We can call such a view a Leibnizian view. Leibnizian views are the main alternatives to Newtonian accounts of the singularity or oneness of a domain. Here is an example of a Leibnizian view of co-spatiality:

\section{Distance}

The members of a set of points belong to the same space in virtue of the fact that there is a determinate distance relation between any arbitrary pairs of them.

According to Distance, what makes it the case that two points are in the same space is the simple fact that there is a determinate distance between the two. No singularity or oneness is the ground of co-spatiality and the relation of co-spatiality is not just a structural or logical relation. Whether Distance is correct or not, it illustrates a possible view that denies Newtonianism about relations of co-spatiality.

Here, I want to offer a Leibnizian view of phenomenal unity. The view is Leibnizian in the sense that it grounds unity in certain conditions over the local relations among the experiences that a subject has at each moment. I call this alternative the connectivity account. The intuitive idea behind the connectivity account is that unity can be understood in terms of the connectivity of experiences, where connectivity is in turn analyzed in terms of the existence of chains of experiences of relations between experiences. ${ }^{10}$

We can experience many specific relations among the objects, events or facts. For example, we can experience temporal relations: "I heard the shattering as I saw the plate hit the floor." We can experience spatial relations: "do you hear the sound as coming from the engine? We can experience causal relations: "I saw the first billiard ball make the other ball move." The set of relations that we can experience is very rich and its members go beyond temporal, spatial and causal relations. This is, of course, a

9 Tye 2003 seems to ground unity the oneness of content. Peacocke 2013 seems to ground unity in the oneness of the subjects of experience. Arguably, these views are also Newtonian.

${ }^{10}$ I develop the Leibnizian alternative in more detail in Masrour 2013. 
controversial claim, but I take it for granted here.

Experiences of specific relations are not experiences of relations between experiences. They are experiences of relations between what experiences present. In other words, they are experiences of relations between the items that figure in the contents of experiences. But we can define a derivative relation among experiences that obtains in virtue of experiences of specific relations. We can thus define a relation that I call binding:

\section{Binding}

Two experiences are bound together iff they are connected by an experience of a specific relation.

We can use the idea of binding to define a weaker relation that can obtain between experiences even when they are not bound:

\section{Unity Path}

There is a unity path between two experiences Em and En iff Em is bound with En or there is an Er such that Em is bound with Er and there is a unity path from Er to En.

It seems plausible that all of the experiences that comprise a unified state of consciousness are connected with each other through unity paths. In fact, this might be the fundamental fact in virtue of which experiences are phenomenally unified. Let us say that an experience is a member of a unity path iff either it is one of the experiences that are connected by the path or it is one of the experiences of relation that binds the other members of the path. We can then characterize the core tenet of the connectivity view in the following manner:

\section{Connectivity Thesis}

The most fundamental personal-level fact in virtue of which a set of experiences, $\mathrm{S}$, is phenomenally unified is the fact that there is a unity path, $\mathrm{P}$, such that all members of $\mathrm{S}$ are members of $\mathrm{P}$.

The Connectivity Thesis is the core thesis of the connectivity view. This view grounds phenomenal unity relations in the existence of unity paths and facts about membership in the unity path. One way to think about the grounding relation between unity and unity paths is to think of unity paths as determinate versions of the determinable relation of phenomenal unity. Intuitively, determinables are instantiated in virtue of the instantiation of their determinates. So it makes sense to assume that phenomenal unity is grounded in unity paths.

I have argued elsewhere that the connectivity view is dialectically more attractive than Newtonian views. ${ }^{11}$ The view is ampliative in that its explanandum (phenomenal unity) and explanans (connectivity) are sufficiently removed from each other. It covers a broader domain because it gives a unified treatment of synchronic and diachronic unities. It is

${ }^{11}$ See Masrour 2013 
more compatible with the feudal model of cognitive architecture, which in my view (and Bayne's view) is the preferable model of cognitive architecture. Finally, it has a better chance to resist skepticism about phenomenal unity.

Here, I want to use the connectivity view to raise my main question for Bayne: what is the justification for choosing his mereological view over the connectivity view? If Bayne wants us to embrace the mereological view, he needs to answer this question.

\section{The Mereological Account vs. the Connectivity Account}

As remarked in the previous section, my main question for Bayne is why we should prefer the mereological account to the connectivity view that I presented in the previous section. This assumes that adopting the mereological view commits Bayne to rejecting the connectivity view. And this does not follow directly from Bayne's commitment to the Mereological Thesis. In other words, it is not completely clear that Bayne's commitment to the Mereological Thesis commits him to a Newtonian view. Whether Bayne is committed to Newtonianism depends also his view of mereology and, as we saw earlier, Bayne does not say much about mereology. To see the dependence of this issue on mereology we can consider the following mereological principle:

\section{Grounded Mereological Connectivity}

A set of experiences, $\mathrm{S}$, form an experiential whole in virtue of the fact that there is a unity path, $\mathrm{P}$ such that all members of $\mathrm{S}$ are members of $\mathrm{P}$.

Grounded Mereological Connectivity and Bayne's Mereological Thesis together entail the Connectivity Thesis. That is, if Bayne accepts Grounded Mereological Connectivity, then he would be committed to the thesis that a set of experiences is unified in virtue of the fact that its members all belong to a unity path. If so, Bayne's view will not be a Newtonian view. So, the mereological account and the connectivity account are compatible with each other.

There is also a weaker thesis in the ballpark of Grounded Mereological Connectivity that is compatible with Bayne's mereological account:

\section{Neutral Mereological Connectivity}

A set of experiences, $\mathrm{S}$, form an experiential whole iff there is a unity path, $\mathrm{P}$ such that all members of $\mathrm{S}$ are members of $\mathrm{P}$.

In conjunction with Bayne's mereological account, Neutral Mereological Connectivity entails that a set of experiences is unified iff its members all belong to a unity path. If Bayne accepts Neutral Mereological Connectivity then his account will be coextensive with the connectivity account. There would still be a substantive disagreement between Bayne's view and the connectivity view in that on Bayne's view phenomenal unity obtains 
in virtue of the existence of a total state of consciousness but on the connectivity model the experiences are unified in virtue of the fact that they form a connected set.

The above observations show that Bayne's mereological view might be necessarily coextensive or even a specific version of the connectivity view. However, Bayne's characterization of phenomenal unity seems to imply that his view is incompatible with the grounded or the neutral versions of Mereological Connectivity. For example, he writes:

Consider again what it's like to hear a rumba playing on the stereo whilst seeing a bartender mix a mojito. These experiences might be subject unified insofar as they are both yours. They might also be representationally unified, for one might hear the rumba as coming from behind the bartender. But over and above these unities is a deeper and more primitive unity: the fact that these two experiences possess a conjoint experiential character. (Bayne, Ibid., p.10)

Bayne characterizes phenomenal unity as over and above subject unity and representational unity. Furthermore, he regards this form of unity as a form of "conjoint" phenomenal character that is "more primitive" than representational and subject unity. Bayne's characterization of representational unity is not equivalent to my characterization of connectivity, but as the example suggest (hearing the rumba as coming from behind the bartender), some cases of what he calls representational unity are cases of what I call connectivity. So Bayne is committed to the view that phenomenal unity makes a contribution to the overall phenomenal character of experience that is over and above the contribution of connecting experiences and is a purely logical or structural matter.

These considerations suggest that Bayne is committed to rejecting Grounded Mereological Connectivity. Since phenomenal unity makes a contribution to phenomenal character that is over and above the contribution of connectivity then phenomenal unity does not obtain in virtue of connectivity. Moreover, if by "deeper" and "more primitive" Bayne means more fundamental in the metaphysical sense, then Bayne has to reject mereological connectivity.

But if so, then it is natural to also hold that Bayne is committed to rejecting Neutral Mereological Connectivity. For, if phenomenal unities are not grounded in connectivity, then it would be mysterious why they should necessarily go with connectivity in the way that Neutral Mereological Connectivity suggests. Note that one cannot hold that connectivity is grounded in phenomenal unity because facts about connectivity are more specific (or determinate) than facts about phenomenal unity. The fact that my visual experience of the bartender and my auditory experience of the rumba are unified cannot be the ground for the fact that I experience the sound of the rumba as coming from behind the bartender. Bayne might respond that it is the fact that some connectivity relation obtains between the two experiences that is grounded in phenomenal unity. But this would violate the principle that existential generalizations are grounded in their instances. Perhaps Bayne denies this principle. But if so, it would be nice to know why. ${ }^{12}$

12 Reference 
One upshot of the above considerations is that Bayne is committed to what we might call Independence:

\section{Independence}

We can have unified but disconnected experiences.

Let us call unified but disconnected experience bare unities. A unified state of consciousness consisting solely of a visual experience of a red wall, an experience of sadness, and the experience associated with the thought that broccoli is good for health would be an example of a bare unity. ${ }^{13}$ If there can be bare unities then Independence is true and since the connectivity view implies the impossibility of bare unities, then the connectivity view is false.

Does Bayne reject the connectivity view because he accepts Independence? But what would be the justification for accepting Independence? One possible reply is that we should accept Independence because bare unities are conceivable. ${ }^{14}$ But it is not clear that we can conceive of bare unities, at least not so according to the conceptual sense of conceivability. Intuitively, a situation is conceivable in the conceptual sense when it is left open by our concepts. In other words, a conceptually conceivable situation is a situation that is not ruled out by the contents of our concepts. But at the moment, we don't know whether bare unities are ruled out by the contents of our concepts, because whether they are ruled out or not depends on which side of the debate between the connectivity view and Bayne's mereological view is right. Let me elaborate.

The debate between the mereological and the connectivity view is primarily a debate about the metaphysics of phenomenal unity. In general, we should distinguish metaphysical issues about the members of a domain from issues that pertain to the content of the concepts that we use to refer to these members. However, in some cases, there are intimate links between metaphysical issues and conceptual issues. And phenomenal unity is one of those cases. This is because the concept of phenomenal unity is a phenomenal concept and phenomenal concepts borrow their contents from their referents. So if the connectivity view is correct and phenomenal unity obtains in virtue of connectivity, then the concept of phenomenal unity somehow includes the concepts of connectivity. If so, bare unities are conceptually problematic and scenarios containing them would be conceptually inconsistent. But if the mereological view is correct, then the concepts of unity and connectivity are independent from each other and bare unities are conceivable in the conceptual sense.

The upshot of this is that, at this stage of the dialectic, it is not clear whether bare unities are conceivable. Borrowing a term from Van Cleve, one might say that unified but

${ }^{13}$ Let us grant that there is cognitive phenomenology.

${ }^{14}$ Of course, I do not mean to say that all claims to possibility are justified in reference to conceivability. For example, we might come to know the brain mechanisms that are responsible for connectivity and those that are responsible for unity and thus realize that the connection between them is contingent. 
disconnected experiences are weakly inconceivable, where weak inconceivability means their conceivability is not clear to us. ${ }^{15}$ Or, drawing on Chalmers' distinction between prima facie and ideal conceivability, we might say that we are not in the position to say whether bare unities are ideally conceivable - though might be prima facie conceivable. ${ }^{16}$ So, one cannot appeal to conceptual conceivability to justify Independence. Perhaps there are other senses of conceivability under which bare unities are conceivable. And there might be other reasons for accepting Independence. At any rate, if Bayne's reason for rejecting Newtonianism is that he accepts Independence, it would be helpful to tell us what justifies the belief in Independence.

\section{Conclusion}

Bayne's book is an excellent contribution to the literature on unity of consciousness and advances the discussion to a great extent. My main aim here has been to ask a few questions about Bayne's view. The main question concerns Bayne's motivation for accepting the mereological view. Given the availability of alternative views of unity such as the connectivity view, it is desirable that Bayne clarifies his motivation for the mereological account. I have also raised a few questions about Bayne's conception of experiential mereology, the sense of necessity that is involved in the Unity Thesis, the positive motivation for embracing it, and the possibility of introspective support the unity judgment. I am looking forward to Bayne's answer to these questions.

\section{Works Cited}

Bayne, T., \& Chalmers, D. (2003). What is the Unity of Consciousness? In A. Cleeremans ed. The Unity of Consciousness: Binding, Integration, and Dissociation, 23-58.

Bayne, T. (2010). The Unity of Consciousness. Oxford University Press, USA.

Chalmers, D. (2002) Does Conceivability Entail Possibility? In Gendler, T., \& Hawthorne, J. (Eds.) Conceivability and Possibility, 145-200. Oxford University Press.

Correia, F., \& Schnieder, B. (Eds.). (2012). Metaphysical Grounding: Understanding the Structure of Reality. Cambridge University Press.

Dainton, B. (2006). Stream of Consciousness: Unity and Continuity in Conscious Experience. Taylor \& Francis.

Fine, K. (2010). Some Puzzles of Ground. Notre Dame Fournal of Formal Logic, 51(1), 97-118.

Fine, K. (2012a). Guide to Ground. In Correia, F., \& Schnieder, B. (Eds.) Metaphysical Grounding: Understanding the Structure of Reality, 37-80. Cambridge University Press.

${ }^{15}$ Van Cleve 1983

16 See Chalmers xx 
Fine, K. (2012b). The Pure Logic of Ground. The Review of Symbolic Logic, 5(1), 1-25.

Hurley, S. L. (1998). Consciousness in Action. Harvard University Press.

Lockwood, M. (1989). Mind, Brain and the Quantum. Oxford: Basil Blackwell.

Masrour, F. (2013). Unity of Consciousness: In Defense of a Leibnizian View. In Christopher Hill and David Bennett (Eds.) Sensory Integration and the Unity of Consciousness, Cambridge: MIT Press. (Forthcoming)

Nagel, T. (1974). What is it Like to be a Bat? The philosophical review, 83(4), 435-450.

Peacocke, C. (Ed.). (1994). Objectivity, Simulation and the unity of consciousness: current issues in the philosophy of mind. British Academy.

Rosen, G. (2010). Metaphysical Dependence: Grounding and Reduction. In eds Hale, B. \& Hoffman, V. (Eds.) Modality: Metaphysics, Logic, and Epistemology, 109-36. Oxford University Press.

Shaffer J. 2009 "On What Grounds What," Metametaphysics, eds. Chalmers, Manley, and Wasserman 347-83: Oxford University Press

Tye, M. (2003). Consciousness and Persons: Unity and Identity. MIT Press.

Van Cleve, J. (1983). Conceivability and the Cartesian Argument for Dualism. Pacific Philosophical Quarterly, 64, 35-45.

Van Gulick, R. (2013). Phenomenal Unity, Representation and the Self. Philosophy and Phenomenological Research, 86(1), 209-214. 